\title{
Key Roles for MYC, KIT and RET signaling in secondary angiosarcomas
}

\author{
E Styring ${ }^{\star}, 1,2$, J Seinen ${ }^{3}$, M Dominguez-Valentin ${ }^{2}$, H A Domanski ${ }^{4}$, M Jönsson ${ }^{2}$, F V von Steyern ${ }^{1}$, \\ H J Hoekstra ${ }^{3}$, A J H Suurmeijer ${ }^{5}$ and M Nilbert ${ }^{2,6}$ \\ ${ }^{1}$ Department of Orthopedics, Section III, Clinical Sciences, Lund University, 22185 Lund, Sweden; ${ }^{2}$ Department of Oncology, \\ Section V, Clinical Sciences, Lund University, 22185 Lund, Sweden; ${ }^{3}$ Division of Surgical Oncology, Department of Surgery, \\ University Medical Center Groningen, University of Groningen, Hanzeplein 1, PO Box 30.001, 9700 Groningen, The Netherlands; \\ ${ }^{4}$ Department of Pathology, Section V, Clinical Sciences, Lund University, 22185 Lund, Sweden; ${ }^{5}$ Department of Pathology, \\ University Medical Center Groningen, University of Groningen, Hanzeplein 1, PO Box 30.001, 9700 Groningen, The Netherlands \\ and ${ }^{6}$ Clinical Research Centre, Hvidovre Hospital, Copenhagen University, 2650 Hvidovre, Denmark
}

Background: Angiosarcomas may develop as primary tumours of unknown cause or as secondary tumours, most commonly following radiotherapy to the involved field. The different causative agents may be linked to alternate tumorigenesis, which led us to investigate the genetic profiles of morphologically indistinguishable primary and secondary angiosarcomas.

Methods: Whole-genome (18k) c-DNA-mediated annealing, selection, extension and ligation analysis was used to genetically profile 26 primary and 29 secondary angiosarcomas. Key findings were thereafter validated using RT-qPCR, immunohistochemistry and validation of the gene signature to an external data set.

Results: In total, 103 genes were significantly deregulated between primary and secondary angiosarcomas. Secondary angiosarcomas showed upregulation of MYC, KIT and RET and downregulation of CDKN2C. Functional annotation analysis identified multiple target genes in the receptor protein tyrosine kinase pathway. The results were validated using RT-qPCR and immunohistochemistry. Further, the gene signature was applied to an external data set and, herein, distinguished primary from secondary angiosarcomas.

Conclusions: Upregulation of MYC, KIT and RET and downregulation of CDKN2C characterise secondary angiosarcoma, which implies possibilities for diagnostic application and a mechanistic basis for therapeutic evaluation of RET-kinase-inhibitors in these highly aggressive tumours.

Angiosarcomas represent a rare and highly aggressive soft tissue sarcoma subtype with a high risk for local recurrences and distant metastases (Nascimento et al, 2008; Antonescu et al, 2009; Neuhaus et al, 2009; Manner et al, 2010; Styring et al, 2010; Guo et al, 2011; Seinen et al, 2012). Angiosarcomas are broadly divided into primary and secondary tumours in relation to whether a predisposing factor, for example, radiotherapy, long-standing lymphedema or chemical exposure can be identified in which case the tumours are classified as secondary angiosarcoma (Stewart and Treves, 1948; Mark et al, 1976; Popper et al, 1978; Body et al, 1987;
Karlsson et al, 1998; Lipshutz et al, 2002; Styring et al, 2010; Shon et al, 2011). About $40 \%$ of secondary angiosarcomas are estimated to develop following radiotherapy for breast cancer (Kirova et al, 2005). Even if the absolute risk of secondary angiosarcoma after radiotherapy for breast cancer is estimated to be $<0.5 \%$, improved breast cancer survival rates imply that an increasing number of individuals are at risk of this rare complication. Altered treatment principles for breast cancer are reflected in a changing presentation of secondary angiosarcomasfrom tumours that present in the upper extremity following many

*Correspondence: Dr E Styring; E-mail: emelie.styring@med.lu.se

Received 23 November 2013; revised 26 May 2014; accepted 1 June 2014; published online 1 July 2014

(c) 2014 Cancer Research UK. All rights reserved 0007-0920/14 
years of long-standing lymphedema, that is Stewart-Treves syndrome, to tumours that present after 5-10 years within the irradiated field (Stewart and Treves, 1948; Body et al, 1987; Billings et al, 2004; Brenn and Fletcher, 2005; Styring et al, 2010).

Morphologically, primary and secondary angiosarcomas appear indistinguishable. Molecular studies have demonstrated upregulation of MYC and KDR in secondary angiosarcomas compared with primary angiosarcomas and atypical vascular lesions (Antonescu et al, 2009; Manner et al, 2010; Guo et al, 2011; Fernandez et al, 2012; Mentzel et al, 2012; Kacker et al, 2013). With the aim to delineate genetic discriminators of primary and secondary angiosarcomas and to identify key tumorigenic pathways in these tumours, we applied whole-genome expression profiling to 26 primary and 29 secondary angiosarcomas.

\section{MATERIALS AND METHODS}

Sample selection and histopathological evaluation. Adult $(>18$ years) patients with angiosarcoma were eligible for the study. Primary angiosarcomas were included irrespective of the patient's sex and the anatomical tumour location. Secondary angiosarcomas were defined as sarcomas located in an irradiated field that developed minimum 3 years after treatment for the primary tumour and were required to show an angiogenic histology that differed from that of the primary tumour (Cahan et al, 1948; Arlen et al, 1971; Cahan, 1998). All secondary angiosarcomas developed following radiotherapy for primary breast cancer. The cases were identified using the Swedish Cancer Registry, the Southern Sweden Pathology Register and the Registry of Histopathology and Cytopathology in the Netherlands (PALGA) and the patients had been treated at the Lund Sarcoma Center, Sweden (covering 1.7 million inhabitants) and at the University Medical Center in Groningen, the Netherlands (covering 1.8 million inhabitants). In total, 46 primary and 37 secondary angiosarcomas were identified from which formalin-fixed, paraffin-embedded tissue could be retrieved from 38 primary and 35 secondary angiosarcomas. Outcome data has previously been presented for the secondary angiosarcomas (Styring et al, 2010; Seinen et al, 2012). All cases were morphologically reviewed by an experienced sarcoma pathologist (HAD) based on Hematoxylin and Eosin-stained sections and complementary immunohistochemical stainings for CD31 (Dako, Glostrup, Denmark; clone JC70A, diluted 1:30), CD34 (Dako, clone QBEnd-10, diluted 1:50) and anti-human cytokeratin (Dako, clone AE1/AE3, diluted 1:50).

\begin{tabular}{|c|c|c|}
\hline & $\begin{array}{c}\text { Primary } \\
\text { angiosarcomas }\end{array}$ & $\begin{array}{c}\text { Secondary } \\
\text { angiosarcomas }\end{array}$ \\
\hline Number of patients & 26 & 29 \\
\hline Age at diagnosis (median, range) & $68(3-91)$ & 68 (50-90) \\
\hline $\operatorname{Sex}(f / m)$ & $16 / 10$ & $29 / 0$ \\
\hline \multicolumn{3}{|l|}{ Location } \\
\hline $\begin{array}{l}\text { Head and neck } \\
\text { Upper extremity } \\
\text { Thoracical wall } \\
\text { Lower extremity } \\
\text { Other locations }\end{array}$ & $\begin{array}{l}6 \\
3 \\
5 \\
4 \\
8\end{array}$ & $\begin{array}{l}- \\
2 \\
27 \\
- \\
-\end{array}$ \\
\hline $\begin{array}{l}\text { Median years between breast } \\
\text { cancer and angiosarcoma }\end{array}$ & - & $8(4-20)$ \\
\hline
\end{tabular}

RNA isolation and gene expression analysis. Adequate tumour material for RNA extraction was available from 26 primary and 29 secondary angiosarcomas. Clinical characteristics are described in Table 1. The tumour blocks were median 11 (2-29) and 6 (2-35) years old in the primary and the secondary angiosarcoma subsets, respectively. Biological replicates (from different tumour areas in two primary and five secondary angiosarcomas) were included. Macro-dissection of non-necrotic tumour areas was performed followed by RNA extraction of three $10-\mu \mathrm{m}$ sections using the High Pure RNA Paraffin Kit (Roche, Castle Hill, Australia) according to the manufacturer's instructions. Concentrations of RNA were determined using a NanoDrop Spectrophotometer (NanoDrop Technologies, Wilmington, DE, USA) and samples yielding sufficient RNA (350 ng) with 260/280 ratios $>1.8$ were selected. Gene expression analysis was performed at the SCIBLU Genomics Centre, Lund University, Sweden. The Illumina Beadarray (HumanWG-6 v4 Expression Beadchip; Illumina, San Diego, CA) system was used according to the manufacturer's instructions. Expression data were uploaded and processed in the GenomeStudio software (Illumina). Data were normalised using background correction and the cubic spline method (Workman et al, 2002). RefSeq features with a detection $P$-value $\leqslant 0.01$ in at least $80 \%$ of the samples were included, leaving 14382 features for further analysis. The data were uploaded into MeV 4.7.4 (Saeed et al, 2003) where they were $\log 2$-transformed and median-centered across assays. Unsupervised hierarchical clustering was performed using the Pearson Correlation and average linkage clustering. All replicates clustered together, which motivated inclusion of one of the replicate signatures in the further analysis. Significance analysis for microarrays (SAM) (Tusher et al, 2001) was used to identify differentially expressed genes in primary and secondary angiosarcomas with a false discovery rate (FDR) of $0 \%$ and a fold change of minimum 2.0. Biological pathways and gene ontology (GO) terms were identified using the web-based Database for Annotation, Visualization and Integrated Discovery 6.7 (DAVID) (Huang da et al, 2009) software with a FDR $\leqslant 5 \%$. Clinical characteristics are described in Table 1. The gene expression data can be accessed through GEO accession number GSE52664.

Validation of gene expression results using reverse transcription quantitative PCR (RT-qPCR). Representative primary $(n=10)$ and secondary $(n=10)$ angiosarcomas with stable gene expression data and sufficient biological material were selected for validation of the DASL results. Expression levels of MYC (Hs99999003_m1), RET (Hs01120027_m1) and CDKN2C (Hs00176227_m1) were determined using RT-qPCR. Briefly, $3 \mu \mathrm{g}$ of total RNA was reversely transcribed (Quantitect Reverse Transcription Kit, Qiagen, Hilden, Germany) and cDNA corresponding to 50 (MYC, UBC, RPS17) or 240 (RET, CDKN2C) ng of total RNA was used as a template in qPCR (Quantitect Probe PCR Kit, Qiagen) with predesigned hydrolysis probe assays (Taqman, Life Technologies, Applied Biosystems, Warrington, UK). The UBC (Hs00824723_m1) and RPS17 (Hs02386586_g1) genes were used as endogenous reference. The cDNA pooled from two hemangioma tissue specimens served as normaliser. All samples were run in triplicate. A dilution series to verify reaction efficiency as well as no template controls were included in each run. Expression ratios were calculated by the $2^{-\Delta \Delta \mathrm{CT}}$ formula. Wilcoxon's rank sum test was used to compare expression ratios between primary and secondary angiosarcomas and the results were visualised using scatterplots.

Immunohistochemical expression of target proteins. Immunohistochemical expression was evaluated in $4-\mu \mathrm{m}$ sections from tissue microarray blocks (RET, KIT, CDKN2C) or regular tumour blocks (KDR). The antibodies used were KIT (A4502, Dilution $1: 400$, Dako), RET (MA1-26379, Dilution 1:25, Thermo Scientific, Waltham, MA, USA), CDKN2C (NB120-3216, Dilution 
$1: 25$, Novus Biologicals, Cambridge, UK) and KDR (Clone 55B11, Dilution 1:100, Cell Signaling, Danvers, MA, USA). The KIT staining was defined as positive or negative while the remaining stainings were graded in three-tier scales (Antonescu et al, 2009). All stainings were independently scored by two investigators (ES and MN) with agreement in $>95 \%$ of the cases. Correlation between the gene expression analysis and the immunohistochemical result was evaluated using Pearson's product-moment correlation test. Comparison between the immunohistochemical expression patterns in primary and secondary angiosarcomas was assessed using Wilcoxon's rank sum test with statistical significance set at $P<0.05$.

External validation. To validate the 103 -gene signature identified in primary $v s$ secondary angiosarcomas, we applied our gene signature to the E-MEXP-3271 data set consisting of 7 primary and 18 secondary angiosarcomas of which the latter had developed following radiotherapy for breast cancer (Hadj-Hamou et al, 2012). A gene expression centroid was constructed by averaging the expression values of the samples in primary and secondary angiosarcomas for each gene in order to establish a signature classifier for nearest centroid classification. A sample from the external data set was assigned to either of the two subsets based on the maximum Pearson correlation of its centroid expression to the angiosarcomas centroid values. Further, we applied the external transcriptome signature for secondary angiosarcomas (HadjHamou et al, 2012) to our data using supervised hierarchical clustering.

\section{RESULTS}

Target genes and key pathways. Unsupervised hierarchical cluster analysis did not separate primary from secondary angiosarcomas (Figure 1). The SAM analysis, however, identified 103 genes that were significantly deregulated comparing primary and secondary angiosarcoma (Figure 2 and Supplementary Table 1). In secondary angiosarcoma, 54 genes, including $M Y C$, KIT and RET, were upregulated and 49 genes, including CDKN2C, were downregulated (Table 2 and Supplementary Table 1). Additional genes with fold changes $>2.0$, some not previously described, were included but were not limited to, UNC5A, CTLA4, ISLR2, ICOS, RAB17, FLT4 and RASGRP3. The DAVID analysis identified significant upregulation of the receptor protein tyrosine kinase pathway (EC number 2.7.10.1; FDR 4.4\%, $P<0.01$ ) based on overrepresentation of, for example, RET, KIT and FLT4.

In primary angiosarcomas, SAM analysis identified 49 upregulated genes, which included NTSR-1, ANKRD1 and CDKN2C. No significant deregulated pathway was identified, but seven GOterms, including cytokine receptor activity, regulation of cell size, the cell membrane and cell adhesion were enriched in primary angiosarcomas compared with secondary angiosarcomas.

RT-qPCR. RT-qPCR confirmed significant $(P<0.005)$ upregulation of $M Y C$ and $R E T$ and downregulation of CDKN2C in secondary angiosarcomas compared with primary angiosarcomas and hemangioma (Figure 3).

Immunohistochemical profiles. Immunohistochemical stainings focused at key target proteins with differential expression between primary and secondary angiosarcomas. KDR was highly expressed in 36 out of 39 secondary angiosarcomas and was thus significantly over-expressed secondary angiosarcomas (Figure 4). The Pearson's product-moment correlation test showed significant correlation between the immunohistochemical staining and the gene expression profile for $\mathrm{KDR}\left(r=0.6 ; P=3 \times 10^{-7}\right)$. Also KIT expression showed significant correlation between the immunostaining and the gene expression profile $(r=0.33 ; P=0.01)$, but did not reveal
Green: primary

Blue: secondary

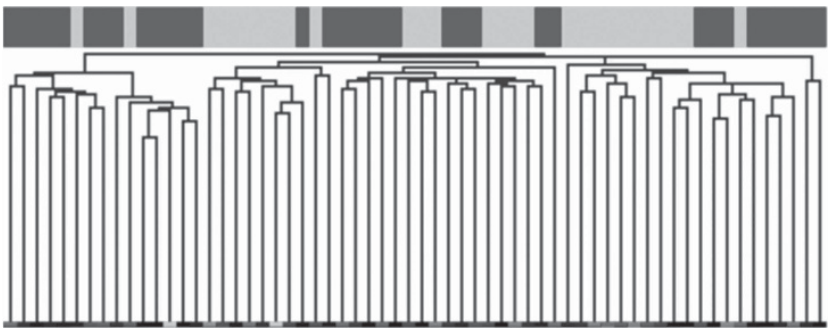

Figure 1. Unsupervised hierarchical clustering of the 28 primary (green) and 34 secondary (blue) angiosarcomas (X-axis). Samples with similar gene expression profiles cluster together. The full heat map is available upon request from the corresponding author.

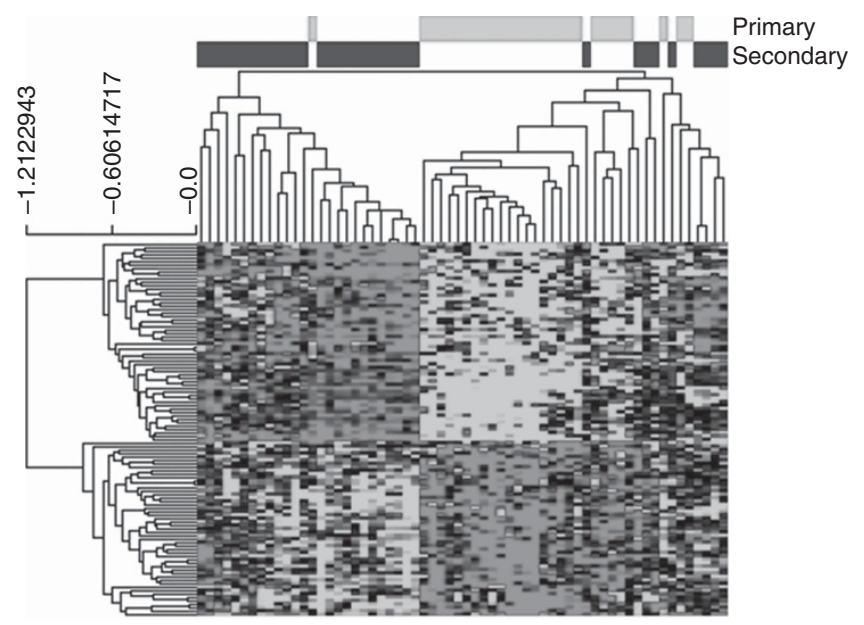

Figure 2. Heat map (SAM analysis) of the 103 genes ( $Y$-axis) expressed at significantly different levels between 28 primary (green) and 24 secondary (blue) angiosarcomas. Samples with similar gene expression profiles cluster together on the $\mathrm{X}$-axis. Upregulated expression is marked with red, and downregulated with green and black reflects no difference in expression levels.

differential immunostaining between primary and secondary angiosarcomas. For RET and $\mathrm{CDKN} 2 \mathrm{C}$ immunostaining and gene expression, data were not significantly correlated, which suggest other or more complex mechanisms of action than protein or gene overexpression.

External validation. The 103-gene signature identified between primary and secondary angiosarcomas in our series was applied to the sample set used by Hadj-Hamou et al (2012) (accession number E-MEXP-3271). The 103-signature achieved separation of the 25 tumours of the external data set into primary and secondary angiosarcoma (Figure 5). The more limited 53-gene signature suggested by Hadj-Hamou et al (2012) was conversely applied to our data set. However, only 29 genes were shared and they did not allow for separate clustering between primary and secondary angiosarcomas (data not shown).

\section{DISCUSSION}

Primary and secondary angiosarcomas in our series show expression profiles with 103 significantly deregulated genes (Figure 2 and Supplementary Table 1). Key target genes between 
Table 2. Selected deregulated genes with their respective fold changes

\begin{tabular}{|l|l|c|c|}
\hline Gene & Definition & Chromosome & Fold change \\
\hline MYC & V-myc myelocytomatosis viral oncogene homologue & 8 & 3.7 \\
\hline RET & Ret proto-oncogene (RET-ELE1, MEN2A, MEN2B, RET51) & 10 & 3.0 \\
\hline KIT & V-kit Hardy-Zuckerman 4 feline sarcoma viral oncogene homologue (CD117, C-KIT) & 4 & 2.1 \\
\hline FLT4 & Fms-related tyrosine kinase 4 (FLT4) & 5 & 2.0 \\
\hline CDKN2C & Cyclin-dependent kinase inhibitor 2C (INK4C, p18) & 1 & 0.5 \\
\hline Abbreviation: MEN2 = multiple endocrine neoplasia type 2. & \\
\hline
\end{tabular}
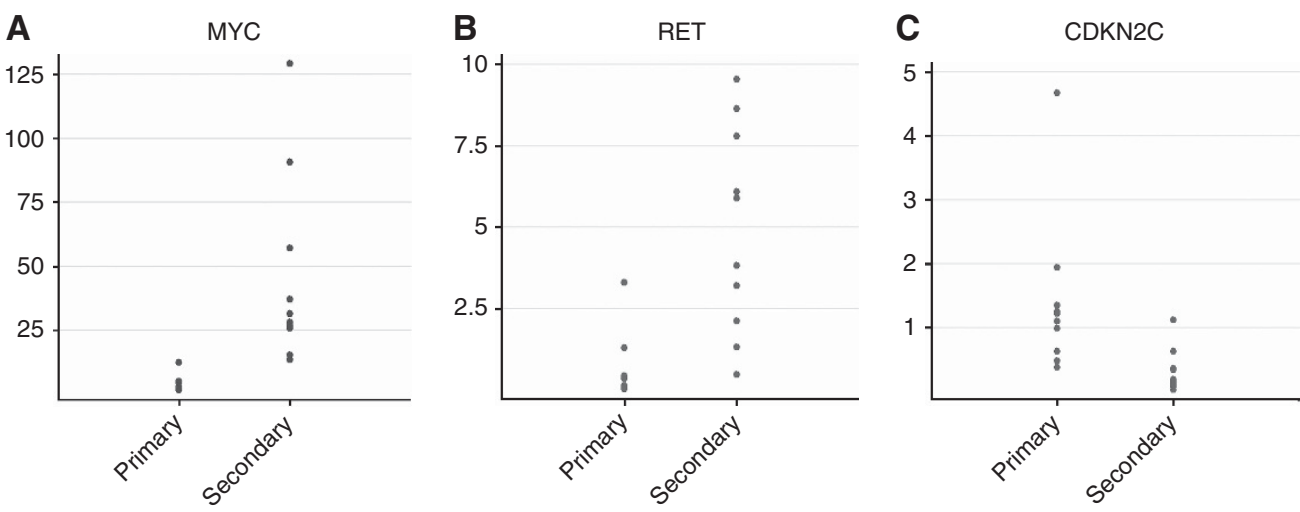

Figure 3. Scatterplots demonstrating the RT-qPCR expression ratios (Y-axis) in primary and secondary angiosarcomas (X-axis) in relation to the pooled reference genes. In secondary angiosarcoma upregulation affects (A) MYC and (B) RET, whereas downregulation is demonstrated for (C) CDKN2C.
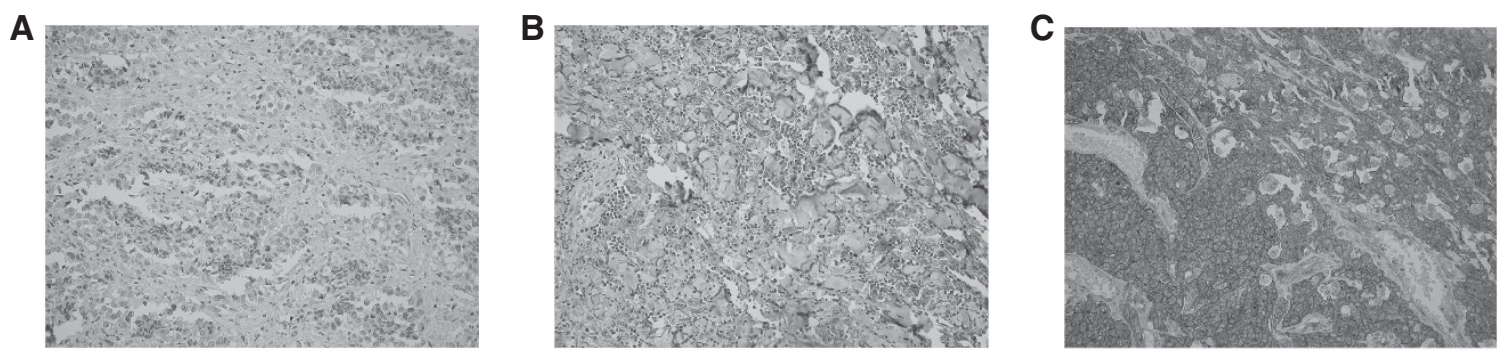

Figure 4. Immunohistochemical staining for KDR Immunohistochemical staining for KDR in (A) a primary angiosarcoma with low expression, $<20 \%$ of the cells positive; (B) secondary angiosarcoma with intermediate expression, $\geqslant 20 \%$ but $<75 \%$; (C) secondary angiosarcoma with high expression, immunoreactivity $>75 \%$ of the cells. Grading was performed according to Antonescu et al, (2009). The expression intensities were determined in the areas with highest staining intensity.

the subsets included MYC, KIT, RET and CDKN2C. Whereas MYC and KIT have been linked to secondary angiosarcoma, involvement of $R E T$ and $C D K N 2 C$ has not previously been described in this tumour type. Deregulation of MYC, RET and CDKN2C was validated using RT-qPCR and immunohistochemistry. Additional genes, not previously described in secondary angiosarcomas, included UNC5A, CTLA4, ISLR2, ICOS, RAB17 and RASGRP3. FLT4, which has been previously been described (Guo et al, 2011) was upregulated with a fold change of 2.0 in our series.

Secondary angiosarcomas showed upregulation of RET signalling and consequently downregulation of the down-stream target CDKN2C (Table 2). Activation of RET linked to mutations in RET and protein overexpression has been reported at high frequencies in radiation-associated thyroid cancer (Bounacer et al, 1997; Collins et al, 2002). Functional studies also support synergistic effects from RET activation and CDKN2C inactivation (De Falco et al, 2007; Joshi et al, 2007; van Veelen et al, 2008; Kulkarni and Franklin, 2011). N-MYC represents a down-stream target of RET and a key step in CDKN2C downregulation. In multiple endocrine neoplasia type 2 and in medullary thyroid cancer, $N-M Y C$ induction has been identified as a key tumorigenic step associated with downregulation of CDKN2C (Kulkarni and Franklin, 2011). Involvement of MYC, RET and FLT4 has been reported in secondary angiosarcomas as well as in other radiation-induced tumours (Antonescu et al, 2009; Manner et al, 2010; Guo et al, 2011; Fernandez et al, 2012; Hadj-Hamou et al, 2012; Mentzel et al, 2012; Kacker et al, 2013). Our findings of MYC, RET and FLT4 upregulation and $C D K N 2 C$ downregulation thus suggest shared tumorigenic mechanisms between different types of radiationinduced tumours.

We found a strong immunohistochemical expression for KDR (Figure 4) in 36 out of 39 secondary angiosarcomas. The upregulation at the protein level was significantly correlated to increased gene expression levels. Our results are consistent with previous reports of upregulation of vascular-specific receptor tyrosine kinases, for example, TIE1, KDR and FLT1 in angiosarcoma (Antonescu et al, 2009). KDR regulates endothelial cell survival, proliferation, migration and vascular formation during 


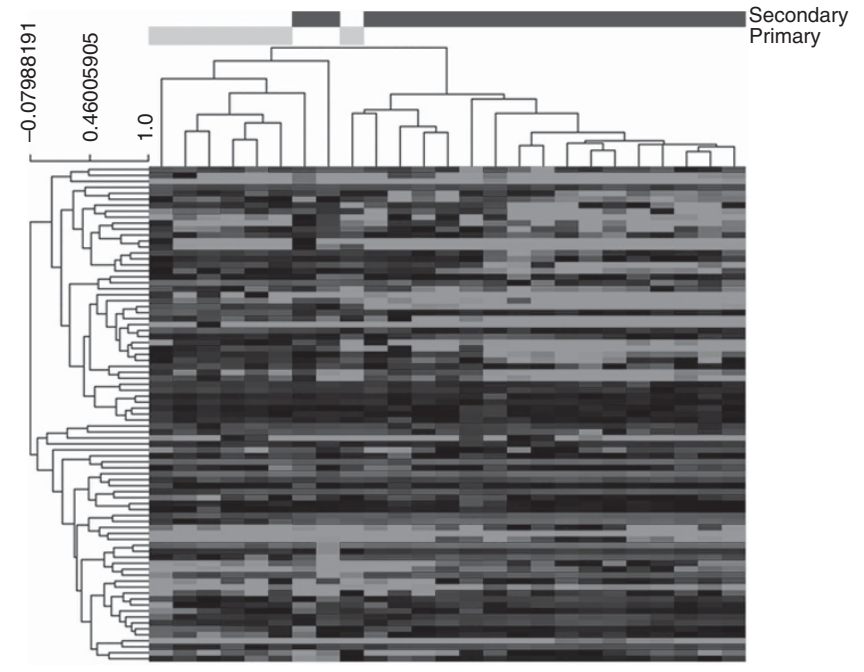

Figure 5. Heat map and hierarchical clustering of our 103-gene signature applied to the external data set E-MEXP-3271 (Hadj-Hamou et al, 2012). Distinct separation is obtained between primary (green) and secondary (blue) angiosarcomas. Samples with similar gene expression profiles cluster together; red: upregualted expression, green: downregulated expression, black: no difference in expression levels.

embryonic development and tumorigenesis (Koch et al, 2011). Activating mutations in KDR have been demonstrated in $10 \%$ of angiosarcomas and have been linked to tumour localisation in the breast (Antonescu et al, 2009).

The 103-gene signature achieved reproducible clustering of primary and secondary angiosarcomas in an external data set (Figure 5). The ability of our signature to cluster independent angiosarcomas suggests a stable and reproducible performance of our results.

Angiosarcomas are aggressive malignant tumours that are generally resistant to chemotherapy and represent a tumour subset where novel therapeutic approaches are needed. Identification of RET signalling as a key feature in secondary angiosarcomas suggests that treatment with RET-kinase-inhibitors may be relevant to evaluate in this tumour subset. Although no specific RET-inhibitor is available, several multi-kinase-inhibitors such as sorafenib, vandetanib and sunitinib, inhibit the RET kinase and cause tumour growth arrest in preclinical models (Herbst et al, 2007). In phase I-II clinical trials, RET inhibitors have shown limited effects in mixed series of soft tissue sarcomas (Maki et al, 2009). Previous trials have not selected patients based on primary $v s$ secondary angiosarcomas or RET status; a response rate of $14 \%$ has been reported in angiosarcomas (Maki et al, 2009). Our data suggest that further studies of RET inhibitors should consider secondary angiosarcoma and evaluate clinical benefit in relation to RET status.

\section{ACKNOWLEDGEMENTS}

We thank Srinivas Veerla for his support in the data analysis. Financial support was granted from the Swedish Research Council, the Swedish Cancer Fund, the Faculty of Medicine, Lund University, Region Skåne and the John och Augusta Perssons stiftelse.

\section{CONFLICT OF INTEREST}

The authors declare no conflict of interest.

\section{REFERENCES}

Antonescu CR, Yoshida A, Guo T, Chang NE, Zhang L, Agaram NP, Qin LX, Brennan MF, Singer S, Maki RG (2009) KDR activating mutations in human angiosarcomas are sensitive to specific kinase inhibitors. Cancer Res 69: 7175-7179.

Arlen M, Higinbotham NL, Huvos AG, Marcove RC, Miller T, Shah IC (1971) Radiation-induced sarcoma of bone. Cancer 28: 1087-1099.

Billings SD, McKenney JK, Folpe AL, Hardacre MC, Weiss SW (2004) Cutaneous angiosarcoma following breast-conserving surgery and radiation: an analysis of 27 cases. Am J Surg Pathol 28: 781-788.

Body G, Sauvanet E, Calais G, Fignon A, Fetissof F, Lansac J (1987) [Cutaneous angiosarcoma of the breast following surgery and irradiation of breast adenocarcinoma]. J Gynecol Obstet Biol Reprod (Paris) 16: 479-483.

Bounacer A, Wicker R, Schlumberger M, Sarasin A, Suarez HG (1997) Oncogenic rearrangements of the ret proto-oncogene in thyroid tumors induced after exposure to ionizing radiation. Biochimie 79: 619-623.

Brenn T, Fletcher CD (2005) Radiation-associated cutaneous atypical vascular lesions and angiosarcoma: clinicopathologic analysis of 42 cases. Am J Surg Pathol 29: 983-996.

Cahan WG (1998) Radiation-induced sarcoma-50 years later. Cancer 82: 6-7.

Cahan WG, Woodard HQ, Higinbotham NL, Stewart FW, Coley BL (1948) Sarcoma arising in irradiated bone; report of 11 cases. Cancer 1: 3-29.

Collins BJ, Chiappetta G, Schneider AB, Santoro M, Pentimalli F, Fogelfeld L, Gierlowski T, Shore-Freedman E, Jaffe G, Fusco A (2002) RET expression in papillary thyroid cancer from patients irradiated in childhood for benign conditions. J Clin Endocrinol Metab 87: 3941-3946.

De Falco V, Castellone MD, De Vita G, Cirafici AM, Hershman JM, Guerrero C, Fusco A, Melillo RM, Santoro M (2007) RET/papillary thyroid carcinoma oncogenic signaling through the Rap1 small GTPase. Cancer Res 67: 381-390.

Fernandez AP, Sun Y, Tubbs RR, Goldblum JR, Billings SD (2012) FISH for MYC amplification and anti-MYC immunohistochemistry: useful diagnostic tools in the assessment of secondary angiosarcoma and atypical vascular proliferations. J Cutan Pathol 39: 234-242.

Guo T, Zhang L, Chang NE, Singer S, Maki RG, Antonescu CR (2011) Consistent MYC and FLT4 gene amplification in radiation-induced angiosarcoma but not in other radiation-associated atypical vascular lesions. Genes Chromosomes Cancer 50: 25-33.

Hadj-Hamou NS, Lae M, Almeida A, de la Grange P, Kirova Y, Sastre-Garau X, Malfoy B (2012) A transcriptome signature of endothelial lymphatic cells coexists with the chronic oxidative stress signature in radiation-induced post-radiotherapy breast angiosarcomas. Carcinogenesis 33: 1399-1405.

Herbst RS, Heymach JV, O’Reilly MS, Onn A, Ryan AJ (2007) Vandetanib (ZD6474): an orally available receptor tyrosine kinase inhibitor that selectively targets pathways critical for tumor growth and angiogenesis. Expert Opin Investig Drugs 16: 239-249.

Huang da W, Sherman BT, Lempicki RA (2009) Systematic and integrative analysis of large gene lists using DAVID bioinformatics resources. Nat Protoc 4: 44-57.

Joshi PP, Kulkarni MV, Yu BK, Smith KR, Norton DL, van Veelen W, Hoppener JW, Franklin DS (2007) Simultaneous downregulation of CDK inhibitors p18(Ink4c) and p27(Kip1) is required for MEN2A-RETmediated mitogenesis. Oncogene 26: 554-570.

Kacker C, Marx A, Mossinger K, Svehla F, Schneider U, Hogendoorn PC, Nielsen OS, Kuffer S, Sauer C, Fisher C, Hallermann C, Hartmann JT, Blay JY, Mechtersheimer G, Hohenberger P, Strobel P (2013) High frequency of MYC gene amplification is a common feature of radiation-induced sarcomas. Further results from EORTC STBSG TL 01/01. Genes Chromosomes Cancer 52: 93-98.

Karlsson P, Holmberg E, Samuelsson A, Johansson KA, Wallgren A (1998) Soft tissue sarcoma after treatment for breast cancer-a Swedish population-based study. Eur J Cancer 34: 2068-2075.

Kirova YM, Vilcoq JR, Asselain B, Sastre-Garau X, Fourquet A (2005) Radiation-induced sarcomas after radiotherapy for breast carcinoma: a large-scale single-institution review. Cancer 104: 856-863.

Koch S, Tugues S, Li X, Gualandi L, Claesson-Welsh L (2011) Signal transduction by vascular endothelial growth factor receptors. Biochem J 437: 169-183. 
Kulkarni MV, Franklin DS (2011) N-Myc is a downstream target of RET signaling and is required for transcriptional regulation of p18(Ink4c) by the transforming mutant RET(C634R). Mol Oncol 5: 24-35.

Lipshutz GS, Brennan TV, Warren RS (2002) Thorotrast-induced liver neoplasia: a collective review. J Am Coll Surg 195: 713-718.

Maki RG, D'Adamo DR, Keohan ML, Saulle M, Schuetze SM, Undevia SD, Livingston MB, Cooney MM, Hensley ML, Mita MM, Takimoto CH, Kraft AS, Elias AD, Brockstein B, Blachere NE, Edgar MA, Schwartz LH, Qin LX, Antonescu CR, Schwartz GK (2009) Phase II study of sorafenib in patients with metastatic or recurrent sarcomas. J Clin Oncol 27: 3133-3140.

Manner J, Radlwimmer B, Hohenberger P, Mossinger K, Kuffer S, Sauer C, Belharazem D, Zettl A, Coindre JM, Hallermann C, Hartmann JT, Katenkamp D, Katenkamp K, Schoffski P, Sciot R, Wozniak A, Lichter P, Marx A, Strobel P (2010) MYC high level gene amplification is a distinctive feature of angiosarcomas after irradiation or chronic lymphedema. Am J Pathol 176: 34-39.

Mark L, Delmore F, Creech Jr. JL, Ogden II LL, Fadell EH, Songster CL, Clanton J, Johnson MN, Christopherson WM (1976) Clinical and morphologic features of hepatic angiosarcoma in vinyl chloride workers. Cancer 37: 149-163.

Mentzel T, Schildhaus HU, Palmedo G, Buttner R, Kutzner H (2012) Postradiation cutaneous angiosarcoma after treatment of breast carcinoma is characterized by MYC amplification in contrast to atypical vascular lesions after radiotherapy and control cases: clinicopathological, immunohistochemical and molecular analysis of 66 cases. Mod Pathol 25: 75-85.

Nascimento AF, Raut CP, Fletcher CD (2008) Primary angiosarcoma of the breast: clinicopathologic analysis of 49 cases, suggesting that grade is not prognostic. Am J Surg Pathol 32: 1896-1904.

Neuhaus SJ, Pinnock N, Giblin V, Fisher C, Thway K, Thomas JM, Hayes AJ (2009) Treatment and outcome of radiation-induced soft-tissue sarcomas at a specialist institution. Eur J Surg Oncol 35: 654-659.

Popper H, Thomas LB, Telles NC, Falk H, Selikoff IJ (1978) Development of hepatic angiosarcoma in man induced by vinyl chloride, thorotrast, and arsenic. Comparison with cases of unknown etiology. Am J Pathol 92: 349-376.
Saeed AI, Sharov V, White J, Li J, Liang W, Bhagabati N, Braisted J, Klapa M, Currier T, Thiagarajan M, Sturn A, Snuffin M, Rezantsev A, Popov D, Ryltsov A, Kostukovich E, Borisovsky I, Liu Z, Vinsavich A, Trush V, Quackenbush J (2003) TM4: a free, open-source system for microarray data management and analysis. Biotechniques 34: 374-378.

Seinen JM, Styring E, Verstappen V, Vult von Steyern F, Rydholm A, Suurmeijer AJ, Hoekstra HJ (2012) Radiation-associated angiosarcoma after breast cancer: high recurrence rate and poor survival despite surgical treatment with R0 resection. Ann Surg Oncol 19: 2700-2706.

Shon W, Ida CM, Boland-Froemming JM, Rose PS, Folpe A (2011) Cutaneous angiosarcoma arising in massive localized lymphedema of the morbidly obese: a report of five cases and review of the literature. J Cutan Pathol 38: 560-564.

Stewart FW, Treves N (1948) Lymphangiosarcoma in postmastectomy lymphedema; a report of six cases in elephantiasis chirurgica. Cancer $\mathbf{1}$ : 64-81.

Styring E, Fernebro J, Jonsson PE, Ehinger A, Engellau J, Rissler P, Rydholm A, Nilbert M, Vult von Steyern F (2010) Changing clinical presentation of angiosarcomas after breast cancer: from late tumors in edematous arms to earlier tumors on the thoracic wall. Breast Cancer Res Treat 122: 883-887.

Tusher VG, Tibshirani R, Chu G (2001) Significance analysis of microarrays applied to the ionizing radiation response. Proc Natl Acad Sci USA 98: 5116-5121.

van Veelen W, van Gasteren CJ, Acton DS, Franklin DS, Berger R, Lips CJ, Hoppener JW (2008) Synergistic effect of oncogenic RET and loss of p18 on medullary thyroid carcinoma development. Cancer Res 68: 1329-1337. Workman C, Jensen LJ, Jarmer H, Berka R, Gautier L, Nielser HB, Saxild HH, Nielsen C, Brunak S, Knudsen S (2002) A new non-linear normalization method for reducing variability in DNA microarray experiments. Genome Biol 3: research0048-research0048.16.

This work is published under the standard license to publish agreement. After 12 months the work will become freely available and the license terms will switch to a Creative Commons AttributionNonCommercial-Share Alike 3.0 Unported License.

Supplementary Information accompanies this paper on British Journal of Cancer website (http://www.nature.com/bjc) 